\section{Standing on shaky ground}

THE catastrophic magnitude-9 Alaska earthquake of 1964 helped usher in the new age of plate tectonics. It also promted a westward migration of seismologists to USGS Menlo Park and the San Andreas fault. But even after 30 years, the underlying triggers of earthquakes remain obscure.

Bill Ellsworth of the

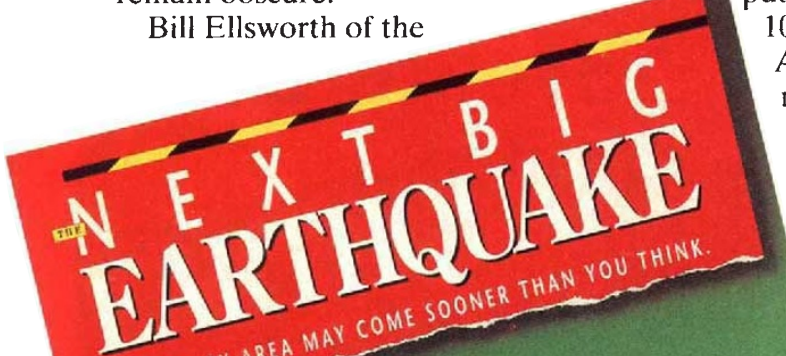

rocks so as to work out failure recurrence periods longer than human history.

Recurrence rates may help in predicting earthquakes, but can say nothing about the causes. This is why Ellsworth, his colleague Stephen Hickman and Stanford geophysicist Mark Zoback have put together a proposal to drill a hole 10,000 metres down into the San Andreas fault, to study its physics, mineralogy and mechanics.

They plan to use careful feasibility studies to select the best location for this hole, in which they would then conduct an extensive programme of geophysical measurements and sampling, before instrumenting the hole as a kind of deep fault 'observatory'. The work will build on the continuing German initiative to drill $10 \mathrm{~km}$ into the crust. More than a hundred people from several countries attended a workshop on the drilling project last December. The idea for an international collaboration is said really to have taken root.

One puzzle the project could solve arises from laboratory simulations of earthquakes. When scaled up to life size, the

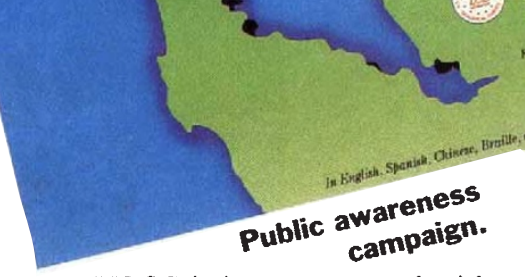

USGS is less concerned with the 'why' than the 'when'. From stress patterns and slip rates in particular fault segments, Ellsworth is sure that earthquakes have a history: many return, time and time again, to the same spot. The trick is finding out when.

The earthquake has not returned to the instrument-festooned Parkfield segment (yet), but other less well-publicized predictions have been uncannily successful. In 1990, for example, David Oppenheimer and colleagues from USGS surveyed a quiet section of the Calaveras fault near Gilroy (40 miles south of Menlo Park) where was an earthquake in 1949. Calculations of the speed at which the fault was moving suggested activity in the near future: there was, indeed, a magnitude-5.2 shock on 16 January 1993. Earthquakes are not entirely random.

Randomness may even be an illusion arising from the brevity of recorded history compared with the recurrence time of earthquakes, especially very large ones. Hence efforts to extend the record by trenching into fault zones and dating

\section{In a state of shock}

IN the next 25 years, the chance of a large earthquake (between magnitudes 7.5 and 8.5) happening on the San Andreas fault near Los Angeles is about 60 per cent better than even. Such forecasts are the stock in trade of the Southern California Earthquake Center (SCEC), a body charged with informing the public about earthquake hazard, and coordinating research efforts into seismic research in southern California.

With the population rising rapidly in the area, seismologists are concerned about the increasing threat of earthquakes to human life. SCEC emerged from a workshop in which seismologists and geologists from seven campuses in southern California felt that they could achieve more together than apart - particularly in terms of funding. In 1991, SCEC was born as one of the National Science Foundation's Science and Technology Centers, with a modest fund of $\$ 1.8$ million a year for 5 years, with a possible extension to 11 . The US Geological Survey (USGS) stepped in with another $\$ 1.2$ million a year, administered through its Pasadena office on Caltech campus.

Lucile Jones of USGS Pasadena takes communications with the public very seriously. Before SCEC was set up, she and her colleagues devised ways to calculate the short-term risk of an earthquake on the San Andreas fault (based on analyses of foreshocks), with graduated levels of alert, and protocols of what emergency services should expect to happen at each level.

At 7.30 p.m. one evening when she was at home, a report of a magnitude 4.6 earthquake came in from near the San Andreas fault near Palm Springs, providing an opportunity to rehearse disaster routines. Jones went back to the office to telephone her colleagues and the state emergency services, and was on the telephone when the magnitude 6 Joshua Tree earthquake happened. Husband and Caltech seismologist Egill Hauksson was at home when the earthquake struck. With no time to get a babysitter, he grabbed the kids and went back to work - only to meet a throng of media people anticipating the Big One on the San Andreas. Comforting a child in her arms and explaining earthquake hazard on television at the same time, Jones "went from being vaguely known to being a celebrity" at a stroke.

The media are, of course, central to this effort. At Caltech there is a media centre with seismometers ticking away, and television screens linked electronically to real-time earthquake monitors that display locations and magnitudes of 